\title{
Fibre intake and incident colorectal cancer depending on fibre source, sex, tumour location and Tumour, Node, Metastasis stage
}

\author{
Alexandra Vulcan ${ }^{1 *}$, Jenny Brändstedt ${ }^{2}$, Jonas Manjer $^{3}$, Karin Jirström ${ }^{4}$, Bodil Ohlsson ${ }^{5}$ and \\ Ulrika Ericson ${ }^{6}$ \\ ${ }^{1}$ Department of Clinical Sciences, Division of Gastroenterology, Lund University, Skåne University Hospital, Malmö, Sweden \\ ${ }^{2}$ Department of Clinical Sciences, Division of Surgery, Lund University, Skåne University Hospital, Malmö, Sweden \\ ${ }^{3}$ Department of Clinical Sciences, Division of Plastic Surgery, Lund University, Skåne University Hospital, Malmö, Sweden \\ ${ }^{4}$ Department of Clinical Sciences, Division of Pathology, Lund University, Skåne University Hospital, Lund, Sweden \\ ${ }^{5}$ Department of Clinical Sciences, Division of Internal Medicine, Lund University, Skåne University Hospital, Malmö, Sweden \\ ${ }^{6}$ Diabetes and Cardiovascular Disease, Genetic Epidemiology, Lund University, Skåne University Hospital, Malmö, Sweden
}

(Submitted 12 December 2014 - Final revision received 18 June 2015 - Accepted 25 June 2015)

\begin{abstract}
Studies on fibre intake and incident colorectal cancer (CRC) indicate inverse associations. Differences by tumour stage have not been examined. We examined associations between fibre intake and its sources, and incidental CRC. Separate analyses were carried out on the basis of sex, tumour location and the Tumour, Node, Metastasis (TNM) classification. The Malmö Diet and Cancer Study is a population-based cohort study, including individuals aged 45-74 years. Dietary data were collected through a modified diet history method. The TNM classification was obtained from pathology/clinical records and re-evaluated. Among 27931 individuals (60\% women), we found 728 incident CRC cases during 428924 person-years of follow-up. Fibre intake was inversely associated with CRC risk $\left(P_{\text {trend }}=0 \cdot 026\right)$. Concerning colon cancer, we observed borderline interaction between fibre intake and sex $(P=0.052)$ and significant protective association restricted to women $\left(P_{\text {trend }}=0 \cdot 013\right)$. Intake of fruits and berries was inversely associated with colon cancer in women $\left(P_{\text {trend }}=0.022\right)$. We also observed significant interactions between intakes of fibre $(P=0.048)$ and vegetables $(P=0.039)$ and sex on rectal cancer, but no significant associations were seen between intake of fibre, or its sources, in either of the sexes. Except for inverse associations between intake of fibre-rich cereal products and N0- and M0-tumours, we did not observe significant associations with different TNM stages. Our findings suggest different associations between fibre intake and CRC depending on sex, tumour site and fibre source. High fibre intake, especially from fruits and berries, may, above all, prevent tumour development in the colon in women. No clear differences by TNM classification were detected.
\end{abstract}

Key words: Colorectal cancer: Fibre: Sex: Tumour, Node, Metastasis classification: Malmö Diet and Cancer Study

Colorectal cancer (CRC) is estimated to be one of the most common forms of cancer in the western world ${ }^{(1,2)}$. In Sweden, it is the fourth most common form of cancer and constitutes $>7 \%$ of the cancer cases ${ }^{(3)}$. The results from epidemiological studies are not wholly consistent, but most epidemiological studies indicate inverse association between fibre intake and incidental $\mathrm{CRC}^{(4)}$. For example, The European Prospective Investigation into Cancer and Nutrition (EPIC) found the risk of getting CRC to be $17 \%$ lower at a high fibre intake ${ }^{(5)}$. The World Cancer Research Fund (WCRF) has, together with the American Institute for Cancer Research, concluded that there is convincing evidence that high intake of fibre, and its sources, is associated with a lower risk for $\mathrm{CRC}^{(4)}$.

There may be several potential mechanisms behind these observations $^{(6)}$. The protective effect of fibre on CRC development has been considered to be the fibre's effect on modulation of colonic transit time, alteration of bile acid metabolism or increase in the production of SCFA ${ }^{(7)}$. It is under debate whether it is mainly total fibre intake that may be of benefit, or subtypes of fibre in specific fibre-rich food sources such as vegetables, fruits, berries or fibre-rich cereal products. Besides fibre, other bioactive components present in fibre-rich foods may have contributed to previously observed associations between fibre intake and CRC. In a large meta-analysis, where higher fibre intake was associated with reduced risk for CRC, the strongest association was seen with whole grain intake, but no evidence of associations of fruit and vegetable fibre was seen ${ }^{(8)}$. Similar findings regarding whole grain were reported by the WCRF, but they also stated that findings regarding fruit and vegetable fibre were in the same direction,

Abbreviations: CRC, colorectal cancer; HR, hazard ratio; MDCS, Malmö Diet and Cancer Study; TNM, Tumour, Node, Metastasis classification.

* Corresponding author: A. Vulcan, fax +46 40337 489, email alexandra.vulcan@med.lu.se 
although they did not reach statistical significance ${ }^{(4)}$. In line with this, high intake of fruit and vegetables has been associated with decreased risk of $\mathrm{CRC}^{(9)}$.

Previous observations have indicated that associations with fibre from fruits and vegetables may differ depending on tumour site ${ }^{(5)}$. In addition, and similar to observations regarding anthropometric risk factors for CRC, the importance of fibre intake may also vary by different clinical tumour stages ${ }^{(10)}$. The association between dietary intake and different stages of CRC has, to our knowledge, not previously been examined.

The objective of the present study was to examine the association between fibre intake and its sources, and incidental CRC, and whether the association differs depending on sex, tumour location and the Tumour, Node, Metastasis (TNM) classification

\section{Methods}

The study was approved by the ethical committee at Lund University (50.91, 2013/803).

\section{Participants}

The Malmö Diet and Cancer Study (MDCS) is a populationbased prospective cohort study in Malmö, Sweden. All men and women living in Malmö between 1991 and 1996, born between 1923 and 1950, were invited to participate. Altogether, 28098 participants ( $40 \%$ ) completed all of the baseline examinations after having given their written, informed consent. Of them, 167 had CRC before or at baseline examination, and were therefore excluded from the study.

\section{Data collection}

At baseline, the participants were asked to fill out questionnaires on socioeconomic, lifestyle and dietary factors. They also registered their cooked meals and underwent a diet history interview. Weight was measured using a balance-beam scale, with subjects wearing only light clothes and no shoes. Height was measured using a fixed stadiometer, calibrated in centimetres. Waist circumference was measured midway between the iliac crest and the lowest rib margin. Body composition was estimated with a single-frequency bio-impedance methodology (BIA 103; RJL Systems). Body fat percentage was calculated using an algorithm provided by the manufacturer.

\section{Dietary data}

Dietary data were gathered through a modified diet history method with a 7-d menu book for registration of meals that varied from day to day, most likely lunch and dinner, cold beverages and nutrient supplements. In addition, the participants were given a 168-item questionnaire for assessment of consumption frequencies and portion sizes of foods that were not covered in the menu book. Finally, a 45-min interview completed the dietary assessment.
The diet analyses were adjusted for the variables called 'method version' and 'season'. Method version was used because of altered coding routines of dietary data introduced in September 1994 in order to shorten the interview time (from $1 \mathrm{~h}$ to $45 \mathrm{~min}$ ). This resulted in two slightly different method versions, before and after September 1994, but did not have any major influence on the ranking of individuals ${ }^{(11)}$. The variable season was divided into spring, summer, autumn and winter depending on when in the year the baseline examination was executed. Dietary change in the past (yes, no) was based on the question 'Have you substantially changed your eating habits because of illness or some other reasons?' The relative validity of the MDCS method was evaluated in the Malmö Food study 1984-1985 ${ }^{(12,13)}$. The Pearson correlation coefficients, adjusted for total energy, between the reference method and the MDCS method were $0.53 / 0.54$ (proteins), $0.69 / 0.64$ (fats), $0.70 / 0.74$ (carbohydrates), 0.69/0.74 (fibres), 0.58/0.50 (breads), 0.73/ 0.74 (cereals), $0 \cdot 24 / 0 \cdot 35$ (rice and pastas), $0 \cdot 77 / 0 \cdot 60$ (fruits) and $0 \cdot 53 / 0.65$ (vegetables) in women and men, respectively.

We used the following variables for daily nutrient intake in this study: total energy (MJ), non-alcoholic energy (MJ), carbohydrates (percentage of energy $(\mathrm{En} \%)$ ), fat (En\%), protein (En\%), fibre (g/MJ), fibre (g), vitamin D ( $\mu \mathrm{g}), \mathrm{Ca}(\mathrm{mg})$ and folate $(\mathrm{mg})$. The following daily intakes of foods were examined: vegetables $(\mathrm{g} / \mathrm{MJ})$, fruits and berries $(\mathrm{g} / \mathrm{MJ})$, fibre-rich cereal products (portions of fibre-rich bread and breakfast cereals/MJ) and red meat $(\mathrm{g})$.

Portions, instead of grams, were used to analyse the sum of fibre-rich cereal products because of different water content and because they usually are consumed in different weights. Standard portion sizes from the National Food Agency in Sweden were used: fibre-rich soft bread ( $50 \mathrm{~g} /$ portion), fibrerich crisp bread (30 g/portion) and fibre-rich breakfast cereals ( $25 \mathrm{~g} /$ portion). Energy-adjusted variables were calculated by dividing dietary intakes by non-alcohol energy intake. Quintiles of the dietary variables were used as exposure categories.

\section{Cancer cases}

We identified 728 cases of CRC from the Swedish Cancer Registry, of which 463 were colon cancer and 265 were rectal cancer, during 428924 person-years of follow-up. Follow-up time was defined as the time from date of enrolment until the date of CRC diagnosis, death, migration or end of follow-up (December 2010), whichever came first. The mean duration of follow-up was $15 \cdot 4$ years.

\section{Tumour characteristics}

Classification of the CRC cases was done by examining clinical and/or pathology records. In addition, the histopathological examination was re-evaluated by a senior pathologist. Colorectal tumours were classified according to the TNM system. The method used to identify the tumour characteristics of CRC has been described elsewhere and the clinicopathological characteristics did not differ between CRC tumours in the MDCS and those in the EPIC cohort ${ }^{(14)}$. The cases identified, until the end of 2008 , were examined and gave a total of 635 cases of CRC. Of them, 
363 were colonic cancers and 272 were rectal cancers. Of the cancer cases where cancer staging was possible, 113 were tumour (T)-stage 1 and 2, 405 were T-stage 3 and 4, 292 were nodenegative (N0) disease, 193 were lymph node positive (N1 and N2) disease, 451 were non-metastatic (M0) disease and 116 were metastatic (M1) disease. Mean follow-up was 13.7 years for the classified cancer cases.

\section{Other variables}

Age was obtained from personal identification numbers. Smokers were divided into three categories: current smokers, ex-smokers and non-smokers. Irregular smoking was defined as current smoking. Physical activity was estimated by asking the subjects to estimate how many minutes per week they spent on seventeen different activities. The duration was multiplied with an activityspecific intensity coefficient, and an overall leisure-time physical activity score was created. The individuals were then divided into quintiles. The level of education was divided into four different categories: $\leq 8$ years, 9-10 years or 11-13 years of education, and university degree. Alcohol intake was divided into four categories: zero, $<15 \mathrm{~g} / \mathrm{d}$ for women and $<20 \mathrm{~g} / \mathrm{d}$ for men, $15-30 \mathrm{~g} / \mathrm{d}$ for women and $20-40 \mathrm{~g} / \mathrm{d}$ for men, and $>30 \mathrm{~g} / \mathrm{d}$ for women and $>40 \mathrm{~g} / \mathrm{d}$ for men. The BMI was calculated from measured weight and length. Current use of menopausal hormonal replacement therapy (MHT) was divided into non-users and users. Regular use of non-steroid anti-inflammatory drugs (NSAID) was divided into users and non-users.

\section{Statistical analyses}

The SPSS statistics (version 22; IBM Corporation) was used for all statistical analyses. Food variables - that is, vegetables, fruits and berries, and fibre-rich cereal products - were log-transformed (e-log) to normalise the distribution before analysis. A very small amount (0.0001) was added before transformation, to handle zero intakes. The general linear model was used when examining baseline continuous characteristics in the different fibre quintiles, and adjustments were made for age, method version and season. The $\chi^{2}$ test was used for categorical variables.

When examining baseline characteristics in cases and noncases, a general linear model was used for the continuous variables and adjustments were made for age and sex when applicable. Additional adjustments for method version and season were made when dietary variables were examined. The $\chi^{2}$ test was used for categorical variables. The Cox proportional hazard regression model was used when estimating hazard ratios (HR) of incident $\mathrm{CRC}$, colon and rectal cancer, and TNM stages, depending on energy-adjusted quintiles of fibre, vegetables, fruit and berries and fibre-rich cereal products. The basic model was adjusted for age, sex (when applicable), season, method version and total energy intake. The full model was additionally adjusted for level of education, smoking, alcohol intake, physical activity, BMI and current use of MHT, when appropriate. These covariates were identified from the literature and indicated potential confounding due to their association with CRC. We also performed the multivariate model excluding BMI, as it might be an intermediate between dietary habits and disease. Finally, we made additional adjustments for regular use of NSAID, and for intakes of folate, red meat, vitamin D or $\mathrm{Ca}$. Years of follow-up were used as the underlying time variable. A test for interaction between sex and fibre or food component with regard to CRC incidence was performed by adding a multiplicative variable ( $\operatorname{sex} \times$ diet quintile (treated as continuous variables)) to the full model. In sensitivity analyses, individuals with a reported dietary change in the past or prevalent cancer (except cervix cancer in situ) were excluded. All tests were two-sided, and statistical significance was assumed at $P<0.05$.

\section{Results}

\section{Baseline characteristics}

Altogether, 16944 women (60.7\%) and 10987 men completed the baseline examinations. Age and reported intake of protein, carbohydrates and folate increased with higher energy-adjusted fibre intake, whereas intakes of fat, vitamin D and alcohol decreased. The men had a higher BMI than the women, but the mean BMI indicated overweight for both sexes. The men also had a higher fibre intake, but when energy-adjusted the women had a higher intake. There were fewer smokers, and more individuals with higher levels of education and physical activity in the highest fibre quintile compared with the lowest (online Supplementary Table S1).

The cases were, compared with non-cases, older and had a higher BMI and a wider waist. Fewer cases had high education, but a higher percentage of cases had a high physical activity level, compared with non-cases. Current use of MHT was less common among cases than among non-cases (Table 1).

\section{Dietary intake and colorectal cancer}

The different statistical models resulted in very similar findings, and therefore only the full multivariate model was chosen when presenting data. High fibre intake was associated with a lower incidence of CRC (HR: 0.72 for highest compared with lowest quintile; $95 \%$ CI 0.55, 0.94; $P$ for trend $=0.026$ ) (Table 2). Of the foods high in fibre, vegetable intake was associated with a lower incidence of CRC (HR: 0.83 for highest compared with lowest quintile; $95 \%$ CI 0.64, 1.07; $P$ for trend $=0 \cdot 048)$. Intakes of fruits and berries or fibre-rich cereal products were not significantly associated with a lower incidence of CRC. Additional adjustments for current use of NSAID and for intakes of folate, red meat, vitamin D or Ca did not change the outcome (data not shown).

In separate analyses depending on tumour location, fibre intake was inversely associated with incidence of colon cancer in women (HR: 0.51 for highest compared with lowest quintile; $95 \%$ CI $0.31,0.75 ; P$ for trend $=0.013)$, but not in men $(P$ for trend $=0.69)$, and we observed a borderline interaction between sex and fibre intake ( $P=0.052)$ (Table 3 ). In addition, women with high intake of fruits and berries had a significantly decreased risk for colon cancer (HR: 0.62 for highest compared with lowest quintile; $95 \%$ CI $0.37,0.98 ; P$ for trend $=0.022$ ). No tendency of protective association was seen in men 
Table 1. Baseline characteristics of cases and non-cases of incident colorectal cancer in the Malmö Diet and Cancer Study cohort (Mean values and standard deviations or percentages)

\begin{tabular}{|c|c|c|c|c|c|c|c|c|c|c|c|c|c|c|c|c|}
\hline & \multirow[b]{2}{*}{$n$} & \multicolumn{2}{|c|}{$\begin{array}{l}\text { Non-cases } \\
\text { (n 27 203) }\end{array}$} & \multicolumn{2}{|c|}{$\begin{array}{l}\text { Cases } \\
(n 728)\end{array}$} & \multirow[b]{2}{*}{$P^{*}$} & \multicolumn{2}{|c|}{$\begin{array}{l}\text { Non-cases women } \\
\quad(n 16572)\end{array}$} & \multicolumn{2}{|c|}{$\begin{array}{l}\text { Cases women } \\
\quad(n \text { 372) }\end{array}$} & \multirow[b]{2}{*}{$P^{*}$} & \multicolumn{2}{|c|}{$\begin{array}{l}\text { Non-cases men } \\
\quad(n 10631)\end{array}$} & \multicolumn{2}{|c|}{$\begin{array}{l}\text { Cases men } \\
\quad(n 356)\end{array}$} & \multirow[b]{2}{*}{$P^{*}$} \\
\hline & & Mean & SD & Mean & SD & & Mean & SD & Mean & SD & & Mean & SD & Mean & SD & \\
\hline Age (years) & 27931 & 58.0 & $7 \cdot 6$ & 61.4 & $7 \cdot 0$ & $<0.001$ & $57 \cdot 3$ & 7.9 & $61 \cdot 7$ & $7 \cdot 1$ & 0.001 & $59 \cdot 1$ & $7 \cdot 0$ & $61 \cdot 1$ & $6 \cdot 8$ & 0.001 \\
\hline $\mathrm{BMI}\left(\mathrm{kg} / \mathrm{m}^{2}\right)$ & 27886 & 25.7 & 4.0 & $26 \cdot 4$ & 4.0 & 0.014 & 25.4 & 4.2 & 26.0 & 4.3 & 0.355 & 26.2 & 3.5 & 26.8 & 3.6 & 0.006 \\
\hline Waist (cm) & 27878 & 84.0 & $12 \cdot 9$ & 87.5 & $13 \cdot 6$ & 0.010 & 77.8 & 10.5 & 79.6 & 11.2 & 0.185 & 93.6 & $10 \cdot 1$ & $95 \cdot 8$ & 10.5 & 0.001 \\
\hline Body fat (\%) & 27760 & $26 \cdot 8$ & $7 \cdot 0$ & 26.5 & $7 \cdot 2$ & 0.069 & $30 \cdot 7$ & $5 \cdot 0$ & 31.6 & 4.9 & 0.428 & $20 \cdot 7$ & $5 \cdot 0$ & $21 \cdot 2$ & $5 \cdot 0$ & 0.100 \\
\hline Fibre intake (g/MJ) & 27931 & $2 \cdot 2$ & 0.6 & $2 \cdot 12$ & 0.6 & 0.192 & $2 \cdot 3$ & 0.7 & $2 \cdot 3$ & 0.6 & 0.117 & $2 \cdot 1$ & 0.6 & 2.07 & 0.6 & 0.828 \\
\hline Fibre intake $(\mathrm{g})$ & 27931 & $20 \cdot 1$ & $7 \cdot 1$ & $20 \cdot 0$ & $6 \cdot 9$ & 0.186 & $19 \cdot 1$ & 6.4 & $18 \cdot 8$ & 6.4 & 0.283 & $21 \cdot 7$ & $7 \cdot 8$ & $21 \cdot 2$ & $7 \cdot 1$ & 0.414 \\
\hline Fat intake (En\%) & 27931 & 38.3 & $6 \cdot 2$ & 38.5 & $6 \cdot 3$ & 0.475 & 37.7 & $6 \cdot 1$ & 37.6 & $6 \cdot 0$ & 0.937 & $39 \cdot 1$ & $6 \cdot 3$ & 39.4 & $6 \cdot 4$ & 0.275 \\
\hline Protein intake (En\%) & 27931 & $15 \cdot 5$ & 2.5 & $15 \cdot 3$ & $2 \cdot 4$ & 0.275 & $15 \cdot 6$ & 2.5 & $15 \cdot 5$ & $2 \cdot 4$ & 0.357 & $15 \cdot 3$ & 2.5 & $15 \cdot 1$ & $2 \cdot 4$ & 0.517 \\
\hline Carbohydrate intake (En\%) & 27931 & $46 \cdot 3$ & $6 \cdot 2$ & $46 \cdot 3$ & $6 \cdot 2$ & 0.777 & $46 \cdot 6$ & $6 \cdot 1$ & $47 \cdot 0$ & 5.9 & 0.646 & $45 \cdot 7$ & $6 \cdot 3$ & 45.5 & 6.5 & 0.399 \\
\hline Vitamin D $(\mu \mathrm{g})$ & 27931 & $8 \cdot 7$ & 4.5 & 8.7 & 4.0 & 0.025 & 8.1 & 4.2 & 7.9 & 3.8 & 0.098 & $9 \cdot 8$ & 4.7 & 9.5 & $4 \cdot 1$ & 0.128 \\
\hline Folate $(\mathrm{mg})$ & 27931 & 290.9 & $307 \cdot 1$ & 284.6 & $388 \cdot 2$ & $0.445 \dagger$ & 286.8 & $310 \cdot 9$ & 265.8 & $119 \cdot 0$ & $0.122 \dagger$ & 297 & $301 \cdot 0$ & 304.3 & 541.3 & $0.647 \dagger$ \\
\hline $\mathrm{Ca}(\mathrm{mg})$ & 27931 & $1144 \cdot 8$ & $425 \cdot 7$ & 1097.5 & $406 \cdot 8$ & 0.007 & $1112 \cdot 2$ & $393 \cdot 2$ & 1084.9 & $398 \cdot 2$ & 0.615 & $1195 \cdot 8$ & 467.4 & $1107 \cdot 6$ & $416 \cdot 1$ & 0.002 \\
\hline Vegetable intake (g) & 27931 & 181.4 & $100 \cdot 4$ & $175 \cdot 8$ & $102 \cdot 0$ & $0.778 † \ddagger$ & 187.0 & $100 \cdot 4$ & $182 \cdot 9$ & 97.7 & $0.060 \dagger \ddagger$ & $172 \cdot 7$ & 99.8 & 169.5 & $106 \cdot 0$ & $0.977 \dagger \ddagger$ \\
\hline Fruit and berry intake (g) & 27931 & 194.4 & $125 \cdot 6$ & $187 \cdot 7$ & 121.6 & $0.237 \dagger \ddagger$ & 208.3 & $124 \cdot 1$ & $203 \cdot 6$ & $109 \cdot 7$ & $0.167 \dagger \ddagger$ & $172 \cdot 9$ & $127 \cdot 3$ & $171 \cdot 1$ & $131 \cdot 1$ & $0.673 \dagger \ddagger$ \\
\hline $\begin{array}{l}\text { Intake of fibre-rich cereal products } \\
\text { (portions/d) }\end{array}$ & 27931 & 0.987 & 1.022 & 0.978 & 0.965 & $0.714 † \ddagger$ & 0.982 & 0.872 & 0.929 & 0.941 & $0.341 \dagger \ddagger$ & 1.078 & $1 \cdot 214$ & 1.029 & 0.988 & $0.775 \dagger \ddagger$ \\
\hline Intake of red meat $(\mathrm{g})$ & 27931 & $59 \cdot 0$ & $35 \cdot 3$ & $60 \cdot 2$ & $36 \cdot 7$ & $0.130 \dagger \ddagger$ & $49 \cdot 6$ & 27.5 & $48 \cdot 7$ & $27 \cdot 1$ & $0.090 \dagger \ddagger$ & 73.7 & $40 \cdot 8$ & $72 \cdot 2$ & 41.3 & $0.770 \dagger \ddagger$ \\
\hline Alcohol intake (g) & 27931 & $10 \cdot 7$ & $12 \cdot 7$ & $11 \cdot 2$ & 14.4 & $0.312 \dagger \ddagger$ & $7 \cdot 7$ & $8 \cdot 7$ & $6 \cdot 4$ & 8.4 & $0.382 \dagger \ddagger$ & $15 \cdot 5$ & $16 \cdot 0$ & $16 \cdot 2$ & $17 \cdot 4$ & $0.122 \dagger \ddagger$ \\
\hline Smoking, ex/current (\%) & 27919 & \multicolumn{2}{|c|}{$33 \cdot 7 / 28.4$} & \multicolumn{2}{|c|}{$38 \cdot 3 / 26 \cdot 2$} & 0.172 & \multicolumn{2}{|c|}{$27 \cdot 8 / 28 \cdot 1$} & \multicolumn{2}{|c|}{$28 \cdot 0 / 26 \cdot 9$} & 0.693 & \multicolumn{2}{|c|}{$43 \cdot 0 / 28 \cdot 8$} & \multicolumn{2}{|c|}{$38 \cdot 3 / 26 \cdot 2$} & 0.220 \\
\hline Education ( $>10$ years) $(\%)$ & 27931 & \multirow{2}{*}{\multicolumn{2}{|c|}{$\begin{array}{l}31.9 \\
19.9\end{array}$}} & \multirow{2}{*}{\multicolumn{2}{|c|}{$27 \cdot 3$}} & 0.040 & \multirow{2}{*}{\multicolumn{2}{|c|}{$\begin{array}{l}30.3 \\
18.7\end{array}$}} & \multirow{2}{*}{\multicolumn{2}{|c|}{$\begin{array}{l}23 \cdot 9 \\
20 \cdot 8\end{array}$}} & 0.011 & \multicolumn{2}{|c|}{$34 \cdot 3$} & \multicolumn{2}{|c|}{30.9} & 0.174 \\
\hline Physical activity high (\%)§ & 27740 & & & \multirow{2}{*}{\multicolumn{2}{|c|}{$\begin{array}{c}23.0 \\
2.0\end{array}$}} & 0.043 & & & & & 0.314 & 21 & & 25 . & & 0.126 \\
\hline Regular use of NSAID (\%) & 27931 & \multicolumn{2}{|c|}{$\begin{array}{l}1.9 \\
2.7\end{array}$} & & & 0.070 & \multicolumn{2}{|c|}{2.2} & \multicolumn{2}{|c|}{$\begin{array}{l}0.0 \\
1.7\end{array}$} & 0.278 & \multicolumn{2}{|c|}{$\begin{array}{c}21.8 \\
3.3\end{array}$} & \multicolumn{2}{|c|}{$\begin{array}{l}2 \cdot 2 \\
2 \cdot 3\end{array}$} & 0.109 \\
\hline $\begin{array}{l}\text { Menopausal hormone therapy } \\
\text { women (\%) }\end{array}$ & 27931 & & & & & & \multicolumn{2}{|c|}{19.4} & 15 & & 0.047 & & & & & \\
\hline
\end{tabular}

En\%, percentage energy; NSAID, non-steroid anti-inflammatory drugs.

* Adjusted for sex and age when appropriate. Calculated with the general linear model for continuous values and $\chi^{2}$ test for categorical values. † Calculated with log-transformed values.

$\ddagger$ Adjusted for age, method, and season, and for sex when appropriate.

$\S$ Physical activity was defined as high when being in the highest quintile of the whole group. 
Table 2. Hazard ratios (HR) of colorectal cancer associated with intakes of fibres and fibre-rich foods in the Malmö Diet and Cancer cohort (Quintile ranges, hazard ratios and $95 \%$ confidence intervals)

\begin{tabular}{|c|c|c|c|c|c|c|c|c|c|}
\hline \multirow[b]{2}{*}{ Quintiles for all } & \multicolumn{3}{|c|}{ All } & \multicolumn{3}{|c|}{ Women } & \multicolumn{3}{|c|}{ Men } \\
\hline & Cases/person-years & $\mathrm{HR}^{*} \dagger$ & $95 \% \mathrm{Cl}$ & Cases/person-years & $\mathrm{HR} \dagger$ & $95 \% \mathrm{Cl}$ & Cases/person-years & $\mathrm{HR} \dagger$ & $95 \% \mathrm{Cl}$ \\
\hline \multicolumn{10}{|l|}{ Fibre (g/MJ) } \\
\hline $0.5-1.7$ & 145/83146 & 1.00 & & $59 / 38020$ & 1.00 & & $86 / 45126$ & 1.00 & \\
\hline $1 \cdot 7-2 \cdot 0$ & $159 / 85385$ & 1.06 & $0.85,1.34$ & $75 / 47379$ & 0.97 & $0.68,1.37$ & $84 / 38005$ & $1 \cdot 12$ & $0.83,1.52$ \\
\hline $2 \cdot 0-2 \cdot 3$ & $152 / 86290$ & 1.00 & $0.79,1.27$ & $71 / 52886$ & 0.80 & $0.56,1 \cdot 15$ & $81 / 33403$ & 1.20 & $0.88,1.64$ \\
\hline $2 \cdot 3-2 \cdot 7$ & $161 / 87418$ & 1.05 & $0.83,1.33$ & $89 / 60183$ & 0.87 & $0.62,1.23$ & $72 / 27234$ & 1.26 & $0.91,1.75$ \\
\hline $2 \cdot 7-8 \cdot 0$ & $111 / 88920$ & 0.72 & $0.55,0.94$ & $78 / 67097$ & 0.66 & $0.47,0.97$ & $33 / 21823$ & 0.72 & $0.47,1.10$ \\
\hline$P$ for trend & & 0.026 & & & 0.078 & & & 0.316 & \\
\hline$P$ for interact & & 0.683 & & & & & & & \\
\hline \multicolumn{10}{|c|}{ Vegetables (g/MJ) } \\
\hline $0-11.1$ & 153/83108 & 1.00 & & $46 / 33753$ & 1.00 & & $107 / 49355$ & 1.00 & \\
\hline $11.1-15.9$ & $167 / 85453$ & $1 \cdot 10$ & $0.88,1.37$ & $71 / 45748$ & $1 \cdot 14$ & $0.78,1.65$ & 96/39702 & 1.08 & $0.82,1.43$ \\
\hline $15 \cdot 9-21 \cdot 1$ & $143 / 86900$ & 0.95 & $0.75,1.20$ & $78 / 53960$ & 1.08 & $0.74,1.56$ & $65 / 32940$ & 0.86 & $0.63,1.84$ \\
\hline $21 \cdot 1-28 \cdot 7$ & $137 / 87167$ & 0.94 & $0.74,1 \cdot 20$ & $87 / 62585$ & $1 \cdot 13$ & $0.78,1.63$ & $50 / 24582$ & 0.87 & $0.62,1.23$ \\
\hline $28 \cdot 7-206 \cdot 7$ & $128 / 88530$ & 0.83 & $0.64,1.07$ & $90 / 69520$ & 1.09 & $0.75,1.59$ & $38 / 19010$ & 0.75 & $0.50,1.11$ \\
\hline$P$ for trend & & 0.048 & & & 0.832 & & & 0.179 & \\
\hline$P$ for interact & ntake & 0.565 & & & & & & & \\
\hline \multicolumn{10}{|c|}{ Fruits and berries (g/MJ) } \\
\hline $0-9.9$ & $159 / 84371$ & 1.00 & & $43 / 31532$ & 1.00 & & $116 / 52838$ & 1.00 & \\
\hline $9 \cdot 9-16 \cdot 1$ & $149 / 85289$ & 0.92 & $0.74,1.16$ & $59 / 43266$ & 0.97 & $0.65,1.46$ & $90 / 42023$ & 0.91 & $0.67,1.20$ \\
\hline $16 \cdot 1-23 \cdot 1$ & 135/86 188 & 0.84 & $0.66,1.07$ & $75 / 54984$ & 0.90 & $0.61,1.32$ & $60 / 31204$ & 0.80 & $0.58,1.10$ \\
\hline $23 \cdot 1-33 \cdot 1$ & $158 / 87608$ & 0.94 & $0.74,1.19$ & $103 / 63812$ & 1.01 & $0.69,1.47$ & $55 / 23796$ & 0.89 & $0.64,1.24$ \\
\hline $33 \cdot 1-224 \cdot 2$ & $127 / 87701$ & 0.82 & $0.64,1.06$ & 92/71971 & 0.84 & $0.57,1.24$ & $35 / 15730$ & 0.86 & $0.58,1.28$ \\
\hline$P$ for trend & & 0.111 & & & 0.205 & & & 0.382 & \\
\hline$P$ for interact & erry intake & 0.898 & & & & & & & \\
\hline \multicolumn{10}{|c|}{ Fibre-rich cereal products (portions/MJ) } \\
\hline $0-0.02$ & $141 / 82963$ & 1.00 & & $61 / 42768$ & 1.00 & & $80 / 40195$ & 1.00 & \\
\hline $0.02-0.06$ & $139 / 85826$ & 1.06 & $0.85,1.340$ & $68 / 52041$ & 0.91 & $0.64,1.31$ & $71 / 33785$ & 1.07 & $0.77,1.47$ \\
\hline $0.06-0.11$ & $157 / 86636$ & 1.00 & $0.79,1.27$ & $88 / 56072$ & $1 \cdot 10$ & $0.78,1.52$ & $69 / 30563$ & $1 \cdot 12$ & $0.81,1.55$ \\
\hline $0.11-0.18$ & $141 / 87238$ & 1.05 & $0.83,1.33$ & $76 / 58106$ & 0.88 & $0.62,1.23$ & $65 / 29131$ & 1.07 & $0.77,1.49$ \\
\hline $0.18-1.29$ & $150 / 88495$ & 0.72 & $0.55,0.94$ & 79/56 578 & 0.89 & $0.61,1.23$ & $71 / 31917$ & 1.04 & $0.75,1.45$ \\
\hline$P$ for trend & & 0.115 & & & 0.277 & & & 0.318 & \\
\hline$P$ for interact & ore-rich cereal products & 0.497 & & & & & & & \\
\hline
\end{tabular}

*Adjusted for sex (man, woman)

† Adjusted for age (continuous), method version (before or after September 1994), season (winter, spring, summer, autumn), total energy (continuous), education (<8 years, 9-10 years, 11-13 years or university degree), smoking (current, ex or never), alcohol intake (zero, $<15 \mathrm{~g} / \mathrm{d}$ for women and $<20 \mathrm{~g} / \mathrm{d}$ for men, $15-30 \mathrm{~g} / \mathrm{d}$ for women and $20-40 \mathrm{~g} / \mathrm{d}$ for men, $>30 \mathrm{~g} / \mathrm{d}$ for women and $>40 \mathrm{~g} / \mathrm{d}$ for men), physical activity (quintiles of physical activity), BMl (continuous) and when appropriate current use of menopausal hormonal replacement therapy (yes, no). 
Table 3. Hazard ratios (HR) of colon cancer associated with intakes of fibres and fibre-rich foods in the Malmö Diet and Cancer cohort

(Quintile ranges, hazard ratios and $95 \%$ confidence intervals)

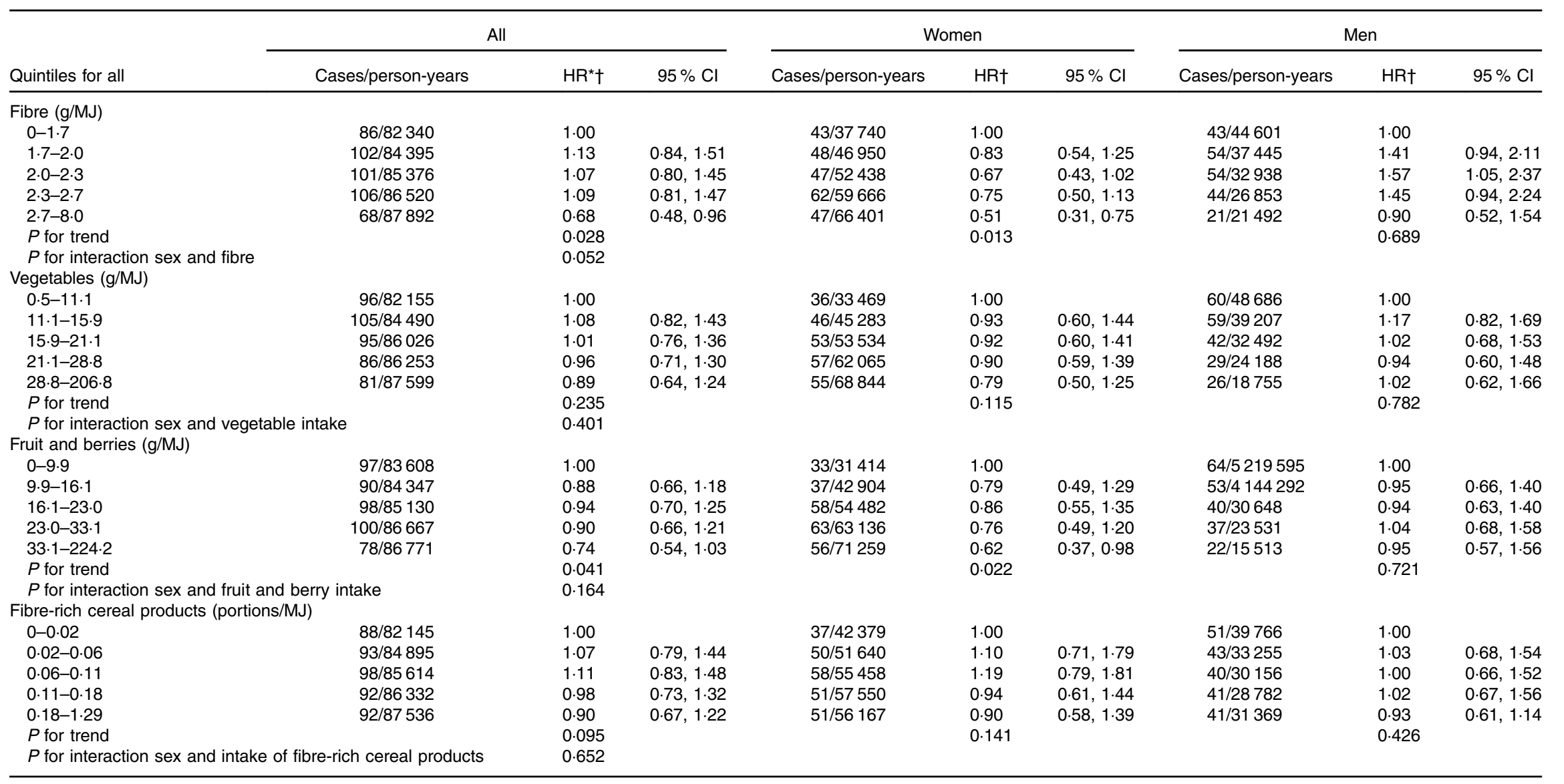

* Adjusted for sex (man, woman).

† Adjusted for age (continuous), method version (before or after September 1994), season (winter, spring, summer, autumn), total energy (continuous), education (<8 years, 9-10 years, 11-13 years or university degree), smoking (current, ex or never), alcohol intake (zero, $<15 \mathrm{~g} / \mathrm{d}$ for women and $<20 \mathrm{~g} / \mathrm{d}$ for men, $15-30 \mathrm{~g} / \mathrm{d}$ for women and 20-40 g/d for men, $>30 \mathrm{~g} / \mathrm{d}$ for women and $>40 \mathrm{~g} / \mathrm{d}$ for men), physical activity (quintiles physical activity), BMI (continuous) and when appropriate current use of menopausal hormonal replacement therapy (yes, no). 
( $P$ for trend $=0.72$ ), but the interaction between intake of fruits and berries and sex did not reach significance $(P=0 \cdot 16)$.

When analysing intakes of fibre and fibre-rich foods and rectal cancer, no significant associations were seen in either of the sexes. However, the risk of developing rectal cancer tended to increase with higher vegetable intake in women (HR: $2 \cdot 22$ for highest compared with lowest quintile; $95 \%$ CI 1.07, 4.61; $P$ for trend $=0.06$ ) (Table 4 ). In contrast, a tendency of protective association between high vegetable intake and rectal cancer was seen in men ( $P$ for trend $=0 \cdot 14)$, and we detected a significant interaction between vegetable intake and sex on rectal cancer $(P=0.039)$. We also observed a significant interaction between fibre intake and sex on rectal cancer $(P=0 \cdot 048)$, but although the associations in men and women seemed to reflect those for vegetable intake the tendencies for fibre intake were less clear $(P$ values for trend $\geq 0 \cdot 26)$.

\section{Fibre intake and relative risk for colorectal cancer of different Tumour, Node, Metastasis stages}

High fibre intake had a tendency towards association with lower risk for T-stage 3 or 4 , together with N-stage 0 , especially in women (data not shown), but no significant association was seen in the final model regarding high fibre intake and association with risk for CRC (Table 5). Intake of fibre-rich cereal products was significantly associated with lower risk for $\mathrm{N}$-stage 0 ( $P$ for trend $=0.015$ ) and for M0 ( $P$ for trend $=0.046$ ), but we did not observe any tendencies of associations with $\mathrm{N}$-stage 1 and 2 or M-stage 1 . When analysing women and men separately, the tendencies of different associations with intake of fibre-rich cereal products depending on $\mathrm{N}$ - and M-stage were mainly seen in men, and the association between fibre-rich cereal products and stage N0 was significant for men (HR: 0.64 for highest quintile compared with lowest; $95 \%$ CI 0.37 ; $P$ for trend $=0.024)$. No other significant associations with tumours classified according to the TNM system were found.

\section{Sensitivity analysis}

When excluding individuals reporting dietary change in the past, the association between fibre intake and risk for CRC was no longer significant, but the risk estimate did not change (HR: 0.72 for highest quintile compared with lowest; $95 \%$ CI $0.52,1.00, P$ for trend $0 \cdot 21$ ). However, the previously inverse association between vegetable intake and risk for CRC disappeared (HR: 1.05 for highest quintile compared with lowest; $95 \%$ CI $0.77,1.42 ; P$ for trend $=0.51$ ). For colon cancer, the inverse associations with intakes of fibre $(P$ for trend $=$ 0.027) and fruits and berries ( $P$ for trend $=0.013$ ) remained significant in women. The association between intake of fibre-rich cereals and N0-stage was no longer significant (HR: 0.62 for highest quintile compared with lowest; $95 \%$ CI 0.32 , 1.23; $P$ for trend $=0.42$ )

When excluding individuals with a prevalent cancer, the association between fibre intake and risk for CRC remained significant ( $P$ for trend $=0.042$ ), but the association between vegetables and risk for CRC disappeared ( $P$ for trend $=0.58$ ).

\section{Discussion}

The results from this large prospective cohort study indicate that a high fibre intake is associated with a lower risk for CRC, or more specifically with a lower risk for colon cancer, in women. When intakes of different fibre-rich foods were analysed, high fruit and berry intake was associated with a lower risk for colon cancer in women. No significant associations were found between fibre intake and its sources, and different clinical stages, except for high intake of fibre-rich cereal products and lower risk for $\mathrm{N}$-stage 0 and $\mathrm{M}$-stage 0 .

The present study confirms the results from other studies that show an association between high fibre intake and lower risk for $\mathrm{CRC}^{(5,8)}$, but in contrast this study did not show a significant overall association with high intake of fibre-rich cereal products. The last may be because of somewhat higher intake levels of whole grain in Sweden ${ }^{(15)}$ than, for example, in the $\mathrm{USA}^{(16)}$, resulting in that most MDCS participants may reach a potential threshold level for protective effects on CRC.

The present study showed a borderline interaction between fibre intake and sex regarding risk for colon cancer, indicating that an inverse association is restricted to women. Other studies have not detected interactions between sex and total fibre intake ${ }^{(17)}$. However, the results from the present study are in analogy with a meta-analysis by Riboli and Norat, which only indicated an association between fruit intake and risk for colon cancer in women $^{(18)}$. The observed association between high intake of fruits and berries and lower risk for colon cancer in women in the present study may be a reflection of the relatively low intake of fruit and berries in Sweden; as seen in the EPIC study other populations have a higher estimated intake ${ }^{(19)}$ and may have intakes well above a potentially protective level. It cannot be ruled out that the differing observations in men and women could be explained by variation in intake levels and accuracy of dietary reporting ${ }^{(20,21)}$. A Swedish national dietary survey showed that women had a higher estimated fibre intake $(25 \mathrm{~g} / 10 \mathrm{MJ}$ per $\mathrm{d})$ than did men $(23 \mathrm{~g} / 10 \mathrm{MJ} \text { per } \mathrm{d})^{(22)}$. The potentially protective role of dietary fibre may also vary depending on exposure to other lifestyle factors of importance in CRC development. In the MDCS cohort, women and men may, for example, have been exposed to different amounts and types of carcinogens, because Malmö is historically a city with a high proportion of workers, and with a high proportion of women being housewives. Another explanation for sex differences may be that the oestrogen levels are lowered in women after menopause, whereas men have another endocrine equilibrium. The intestinal epithelium is an important barrier for luminal factors, and oestrogen has been shown to be important to strengthen the tight junctions in the intercellular spaces ${ }^{(23)}$. Lower oestrogen levels after menopause might increase permeability in the colon, and thus implicate increased risk for penetration of luminal irritants inducing chronic mucosal inflammation, and in the long-term maybe even cancer ${ }^{(24)}$. Anti-carcinogenic compounds, potentially including dietary fibre, may therefore be of greater importance to women.

The mechanisms behind the inverse association between fibre intake and CRC are much thought to be local mechanisms in the colon - for example - reduction of colonic transit time, increase in stool output and frequency, increase in water content of the stool, dilution of colonic content, reduction of 
Table 4. Hazard ratios (HR) of rectal cancer associated with intakes of fibres and fibre-rich foods in the Malmö Diet and Cancer cohort (Quintile ranges, hazard ratios and $95 \%$ confidence intervals)

\begin{tabular}{|c|c|c|c|c|c|c|c|c|c|}
\hline \multirow[b]{2}{*}{ Quintiles for all } & \multicolumn{3}{|c|}{ All } & \multicolumn{3}{|c|}{ Women } & \multicolumn{3}{|c|}{ Men } \\
\hline & Cases/person-years & $\mathrm{HR}^{\star} \dagger$ & $95 \% \mathrm{Cl}$ & Cases/person-years & $\mathrm{HR}+$ & $95 \% \mathrm{Cl}$ & Cases/person-years & $\mathrm{HR} \dagger$ & $95 \% \mathrm{Cl}$ \\
\hline \multicolumn{10}{|l|}{ Fibre (g/MJ) } \\
\hline $0-1.7$ & $46 / 81286$ & 1.00 & & 20/57913 & 1.00 & & 26/23 373 & 1.00 & \\
\hline $1 \cdot 7-2 \cdot 0$ & $58 / 84108$ & 1.18 & $0.79,1.76$ & $34 / 57380$ & 1.74 & $0.98,3 \cdot 10$ & $24 / 26727$ & 0.78 & $0.44,1.37$ \\
\hline $2 \cdot 0-2 \cdot 3$ & $48 / 84915$ & 0.92 & $0.60,1.54$ & $25 / 54710$ & 1.28 & $0.68,2.39$ & $23 / 30205$ & 0.66 & $0.37,1.18$ \\
\hline $2 \cdot 3-2 \cdot 7$ & $56 / 86269$ & 1.01 & $0.66,1.54$ & $23 / 50535$ & 1.26 & $0.65,2.42$ & $33 / 35733$ & 0.77 & $0.44,1.36$ \\
\hline $2 \cdot 7-8 \cdot 0$ & $57 / 87796$ & 0.88 & $0.55,1.42$ & $23 / 41424$ & 1.36 & $0.67,2 \cdot 78$ & $34 / 46372$ & 0.59 & $0.31,1.12$ \\
\hline$P$ for trend & & 0.525 & & & 0.660 & & & 0.263 & \\
\hline$P$ for interact & & 0.048 & & & & & & & \\
\hline \multicolumn{10}{|c|}{ Vegetables (g/MJ) } \\
\hline $0.5-11.1$ & $58 / 80879$ & 1.00 & & $17 / 44410$ & 1.00 & & $41 / 36469$ & 1.00 & \\
\hline $11 \cdot 1-15 \cdot 9$ & $48 / 84578$ & 0.83 & $0.56,1.22$ & 20/50 819 & 1.89 & $0.90,3.96$ & 28/33759 & 0.75 & $0.46,1.21$ \\
\hline $15 \cdot 9-21 \cdot 1$ & $45 / 84854$ & 0.82 & $0.55,1.22$ & $24 / 53103$ & 1.65 & $0.78,3.49$ & $21 / 31750$ & 0.62 & $0.37,1.06$ \\
\hline $21 \cdot 1-28 \cdot 8$ & $54 / 86288$ & 1.01 & $0.69,1.48$ & 28/56 185 & 1.97 & $0.95,4.07$ & $26 / 30103$ & 0.82 & $0.50,1.36$ \\
\hline $28 \cdot 8-206 \cdot 8$ & $60 / 87775$ & 1.09 & $0.74,1.60$ & $36 / 57446$ & $2 \cdot 22$ & $1.07,4.61$ & $24 / 30330$ & 0.71 & $0.42,1.21$ \\
\hline$P$ for trend & & 0.738 & & & 0.062 & & & 0.138 & \\
\hline$P$ for interact & take & 0.039 & & & & & & & \\
\hline \multicolumn{10}{|c|}{ Fruit and berries (g/MJ) } \\
\hline $0-9.9$ & $62 / 82801$ & 1.00 & & $17 / 38567$ & 1.00 & & $45 / 44224$ & 1.00 & \\
\hline $9 \cdot 9-16 \cdot 1$ & 49/83799 & 0.83 & $0.57,2 \cdot 21$ & $15 / 48606$ & 1.48 & $0.69,3 \cdot 15$ & $34 / 35193$ & 0.91 & $0.58,1.43$ \\
\hline $16 \cdot 1-23 \cdot 0$ & $43 / 84665$ & 0.73 & $0.49,1.08$ & 23/53 858 & 0.92 & $0.42,2.03$ & 20/30 807 & 0.62 & $0.36,1.06$ \\
\hline $23 \cdot 0-33 \cdot 1$ & $49 / 86465$ & 0.78 & $0.53,1.17$ & $29 / 60390$ & 1.81 & $0.89,3.69$ & 20/26 075 & 0.69 & $0.40,1.19$ \\
\hline $33 \cdot 1-224 \cdot 2$ & $62 / 86645$ & 1.04 & $0.71,1.52$ & $41 / 60533$ & 1.59 & $0.77,3.29$ & $21 / 26111$ & 0.75 & $0.43,1.30$ \\
\hline$P$ for trend & & 0.960 & & & 0.291 & & & 0.344 & \\
\hline$P$ for interact & rry intake & 0.053 & & & & & & & \\
\hline \multicolumn{10}{|c|}{ Fibre-rich cereal products (portions/MJ) } \\
\hline $0-0.02$ & $50 / 81861$ & 1.00 & & 22/44 322 & 1.00 & & 28/37 538 & 1.00 & \\
\hline $0.02-0.06$ & $45 / 84371$ & 0.94 & $0.62,1.42$ & 22/55 595 & 0.63 & $0.34,1.18$ & 23/28 777 & 1.05 & $0.60,1.84$ \\
\hline $0.06-0.11$ & $54 / 84913$ & $1 \cdot 14$ & $0.77,1.69$ & 29/57 761 & 0.96 & $0.55,1.67$ & $25 / 27151$ & 1.26 & $0.73,2 \cdot 16$ \\
\hline $0.11-0.18$ & $60 / 86244$ & 1.23 & $0.84,1 \cdot 80$ & $25 / 57297$ & 0.79 & $0.45,1.41$ & $35 / 28947$ & 1.62 & $0.98,2.68$ \\
\hline $0.18-1.29$ & 56/86 986 & 0.99 & $0.67,1.48$ & $27 / 46988$ & 0.88 & $0.50,1.54$ & 29/39997 & 0.95 & $0.56,1.63$ \\
\hline$P$ for trend & & 0.696 & & & 0.823 & & & 0.554 & \\
\hline$P$ for interact & re-rich cereal products & 0.612 & & & & & & & \\
\hline
\end{tabular}

* Adjusted for sex (man, woman).

† Adjusted for age (continuous), method version (before or after September 1994), season (winter, spring, summer, autumn), total energy (continuous), education (<8 years, 9-10 years, 11-13 years or university degree), smoking (current, ex or never), alcohol intake (zero, $<15 \mathrm{~g} / \mathrm{d}$ for women and $<20 \mathrm{~g} / \mathrm{d}$ for men, $15-30 \mathrm{~g} / \mathrm{d}$ for women and $20-40 \mathrm{~g} / \mathrm{d}$ for men, $>30 \mathrm{~g} / \mathrm{d}$ for women and $>40 \mathrm{~g} / \mathrm{d}$ for men), physical activity (quintiles of physical activity), BMl (continuous) and when appropriate current use of menopausal hormonal replacement therapy (yes, no). 
Table 5. Hazard ratios (HR) of colorectal cancer stages associated with intakes of fibre and fibre-rich foods in the Malmö Diet and Cancer cohort (Quintile ranges, hazard ratios and $95 \%$ confidence intervals)

\begin{tabular}{|c|c|c|c|c|c|c|c|c|c|c|c|c|c|c|c|c|c|c|}
\hline \multirow[b]{2}{*}{$\begin{array}{l}\text { Quintiles for } \\
\text { all }\end{array}$} & \multicolumn{3}{|c|}{ HR of T-stage 1 and 2} & \multicolumn{3}{|c|}{ HR of T-stage 3 and 4} & \multicolumn{3}{|c|}{$\mathrm{HR}$ of $\mathrm{N}$-stage 0} & \multicolumn{3}{|c|}{$\mathrm{HR}$ of $\mathrm{N}$-stage 1 and 2} & \multicolumn{3}{|c|}{$\mathrm{HR}$ of M-stage 0} & \multicolumn{3}{|c|}{ HR of M-stage 1} \\
\hline & $\begin{array}{c}\text { Cases/ } \\
\text { person- } \\
\text { years }\end{array}$ & $\mathrm{HR}^{\star}$ & $95 \% \mathrm{Cl}$ & $\begin{array}{c}\text { Cases/ } \\
\text { person- } \\
\text { years }\end{array}$ & $\mathrm{HR}^{\star}$ & $95 \% \mathrm{Cl}$ & $\begin{array}{c}\text { Cases/ } \\
\text { person- } \\
\text { years }\end{array}$ & $\mathrm{HR}^{\star}$ & $95 \% \mathrm{Cl}$ & $\begin{array}{c}\text { Cases/ } \\
\text { person- } \\
\text { years }\end{array}$ & $H R^{*}$ & $95 \% \mathrm{Cl}$ & $\begin{array}{c}\text { Cases/ } \\
\text { person- } \\
\text { years }\end{array}$ & $\mathrm{HR}^{\star}$ & $95 \% \mathrm{Cl}$ & $\begin{array}{c}\text { Cases/ } \\
\text { person- } \\
\text { years }\end{array}$ & $\mathrm{HR}^{*}$ & $95 \% \mathrm{Cl}$ \\
\hline \multicolumn{19}{|l|}{ Fibre $(g / M J)$} \\
\hline $0.5-1.7$ & $22 / 74605$ & 1.00 & & 75/75 333 & 1.00 & & $57 / 75118$ & 1.00 & & $34 / 74877$ & 1.00 & & $82 / 75417$ & 1.00 & & $22 / 74618$ & 1.00 & \\
\hline $1 \cdot 7-2 \cdot 0$ & $24 / 75199$ & 1.08 & $0.60,1.94$ & 101/76 264 & $1 \cdot 26$ & $0.93,1.71$ & 67/77 5888 & $1 \cdot 17$ & $0.82,1.67$ & $47 / 75696$ & $1 \cdot 18$ & $0.77,1.83$ & 107/76 312 & 1.23 & $0.92,1.65$ & $26 / 75229$ & 1.20 & $0.67,2 \cdot 12$ \\
\hline $2 \cdot 0-2 \cdot 3$ & $21 / 75628$ & 0.96 & $0.52,1.78$ & 88/76 536 & 1.06 & $0.77,1.46$ & 70/76 343 & 1.17 & $0.82,1.67$ & $33 / 75897$ & 0.85 & $0.53,1.36$ & 93/76 605 & 1.03 & $0.76,1.40$ & $25 / 75692$ & 1.15 & $0.64,2.07$ \\
\hline $2 \cdot 3-2 \cdot 7$ & $30 / 75898$ & 1.40 & $0.78,2.51$ & $75 / 76547$ & 0.89 & $0.64,1.25$ & $58 / 76411$ & 0.98 & $0.67,1.44$ & 40/76 190 & 0.95 & $0.60,1.51$ & 98/76 832 & $1 \cdot 10$ & $0.81,1.50$ & 20/75 771 & 0.89 & $0.47,1.69$ \\
\hline $\begin{array}{l}2 \cdot 7-8 \cdot 0 \\
P \text { for trend }\end{array}$ & $16 / 76063$ & 0.75 & $0.37,1.51$ & $66 / 76733$ & $\begin{array}{l}0.79 \\
0.086\end{array}$ & $0.55,1 \cdot 12$ & 40/76 395 & 0.67 & $0.43,1.03$ & $39 / 76484$ & $\begin{array}{l}0.95 \\
0.708\end{array}$ & $0.60,1.53$ & $71 / 76782$ & 0.77 & $0.55,1.09$ & $23 / 76082$ & $\begin{array}{l}1.11 \\
0.787\end{array}$ & $0.59,2 \cdot 10$ \\
\hline \multicolumn{19}{|l|}{$\begin{array}{l}\text { Vegetables } \\
\text { (g/MJ) }\end{array}$} \\
\hline $0-11.1$ & $22 / 74319$ & 1.00 & & $80 / 74906$ & 1.00 & & $56 / 74879$ & 1.00 & & $39 / 74678$ & 1.00 & & $81 / 75145$ & 1.00 & & 29/74 447 & 1.00 & \\
\hline $11 \cdot 1-15.9$ & $19 / 75136$ & 0.91 & $0.49,1 \cdot 70$ & $88 / 76116$ & 0.90 & $0.64,1 \cdot 27$ & $68 / 75789$ & 1.25 & $0.88,1.79$ & $39 / 75490$ & 1.05 & $0.68,1.63$ & $96 / 76167$ & 1.23 & $0.91,1.66$ & $26 / 75209$ & 0.98 & $0.57,1.67$ \\
\hline $15 \cdot 9-21 \cdot 1$ & $22 / 75816$ & 1.12 & $0.61,2.07$ & $85 / 76453$ & 1.03 & $0.74,1.42$ & $60 / 76426$ & 1.17 & $0.81,1.70$ & $41 / 76185$ & 0.98 & $0.62,1.54$ & $101 / 76893$ & 1.31 & $0.97,1.77$ & $12 / 75634$ & 0.49 & $0.25,0.97$ \\
\hline $21 \cdot 1-28 \cdot 7$ & $34 / 75850$ & 1.77 & $1.00,3.13$ & 72/76 984 & 1.01 & $0.73,1.39$ & $55 / 76255$ & $1 \cdot 13$ & $0.76,1.67$ & $36 / 76085$ & $1 \cdot 10$ & $0 \cdot 70,1 \cdot 72$ & $91 / 76628$ & 1.26 & $0.92,1.73$ & $21 / 75676$ & 0.90 & $0.50,1.63$ \\
\hline $28 \cdot 7-206 \cdot 7$ & 16/76 272 & 0.92 & $0.46,1.85$ & 80/76 954 & 0.93 & $0.67,1.29$ & $53 / 76806$ & 1.14 & $0.76,1.72$ & $39 / 76705$ & 0.98 & $0.60,1.59$ & $81 / 77117$ & $1 \cdot 12$ & $0.80,1.57$ & 28/76 405 & 1.24 & $0.69,2.23$ \\
\hline$P$ for trend & & 0.575 & & & 0.987 & & & 0.914 & & & 0.913 & & & 0.559 & & & 0.922 & \\
\hline \multicolumn{19}{|c|}{ Fruits and berries (g/MJ) } \\
\hline $0-9.9$ & $28 / 74144$ & 1.00 & & $85 / 76165$ & 1.00 & & $65 / 74670$ & 1.00 & & $39 / 74423$ & 1.00 & & $96 / 75035$ & 1.00 & & 25/74 091 & 1.00 & \\
\hline $9 \cdot 9-16 \cdot 1$ & $16 / 75212$ & 0.55 & $0.29,1.02$ & $81 / 76053$ & 0.91 & $0.67,1.24$ & $52 / 75757$ & 1.11 & $0.75,1.63$ & $41 / 75668$ & 0.97 & $0.63,1.49$ & $86 / 76154$ & 0.84 & $0.63,1.37$ & $23 / 75299$ & 1.04 & $0.56,1.94$ \\
\hline $16 \cdot 1-23 \cdot 1$ & $22 / 75663$ & 0.76 & $0.43,1.35$ & 79/76 670 & 0.89 & $0.65,1.22$ & $58 / 76223$ & 0.83 & $0.56,1.23$ & $38 / 75984$ & 0.82 & $0.53,1.29$ & $85 / 76527$ & 0.86 & $0.63,1.16$ & $25 / 75679$ & 0.93 & $0.50,1.72$ \\
\hline $23 \cdot 1-33 \cdot 1$ & $28 / 76245$ & 0.94 & $0.53,1.65$ & $80 / 76336$ & 0.87 & $0.63,1.21$ & $59 / 76794$ & 0.96 & $0.66,1.39$ & $40 / 76608$ & 0.86 & $0.55,1.35$ & $99 / 77231$ & 0.96 & $0.71,1.29$ & $21 / 76202$ & 1.00 & $0.55,1.81$ \\
\hline $33 \cdot 1-224 \cdot 2$ & $19 / 76130$ & 0.71 & $0.38,1.34$ & $80 / 77159$ & 0.92 & $0.66,1.29$ & $58 / 76712$ & 0.95 & $0.66,1.37$ & $35 / 76461$ & 0.79 & $0.49,1.28$ & $85 / 77002$ & 0.86 & $0.62,1 \cdot 18$ & $22 / 76120$ & 0.85 & $0.46,1.55$ \\
\hline$P$ for trend & & 0.928 & & & 0.207 & & & 0.555 & & & 0.219 & & & 0.449 & & & 0.369 & \\
\hline \multicolumn{19}{|c|}{ Fibre-rich cereal products (portions/MJ) } \\
\hline $0-0.02$ & $26 / 74940$ & 1.00 & & 79/75 684 & 1.00 & & $68 / 75613$ & 1.00 & & $29 / 75128$ & 1.00 & & $94 / 75862$ & 1.00 & & 18/74 824 & 1.00 & \\
\hline $0.02-0.06$ & $24 / 75444$ & 0.91 & $0.52,1.60$ & 74/76 086 & 0.95 & $0.69,1.32$ & $51 / 75858$ & 0.81 & $0.56,1 \cdot 17$ & $40 / 75744$ & 1.22 & $0.76,1.97$ & $86 / 76253$ & 0.92 & $0.68,1.24$ & $21 / 75367$ & 1.24 & $0.66,2.34$ \\
\hline $0.06-0.11$ & $23 / 75471$ & 0.86 & $0.49,1.51$ & $91 / 76411$ & 1.17 & $0.86,1.59$ & 70/76 167 & 1.06 & $0.76,1.49$ & $38 / 75822$ & 1.31 & $0 \cdot 82,2 \cdot 10$ & $96 / 76470$ & 1.03 & $0.77,1.37$ & 28/75 579 & 1.64 & $0.90,2.99$ \\
\hline $0.11-0.18$ & $18 / 75907$ & 0.65 & $0.35,1.19$ & $84 / 76792$ & 1.02 & $0.75,1.40$ & $53 / 76423$ & 0.77 & $0.53,1.10$ & $41 / 76354$ & 1.33 & $0.83,2.11$ & $90 / 76839$ & 0.91 & $0.68,1.22$ & 22/75933 & 1.23 & $0.66,2 \cdot 31$ \\
\hline $0.18-1.29$ & $22 / 75631$ & 0.74 & $0.41,1.33$ & $77 / 76440$ & 0.84 & $0.61,1.16$ & $50 / 76095$ & 0.67 & $0.46,0.97$ & $45 / 76094$ & $1 \cdot 21$ & $0.76,1.93$ & $84 / 76525$ & 0.77 & $0.57,1.04$ & $27 / 75688$ & 1.36 & $0.73,2.52$ \\
\hline$P$ for trend & & 0.126 & & & 0.212 & & & 0.015 & & & 0.573 & & & 0.046 & & & 0.813 & \\
\hline
\end{tabular}

* Adjusted for sex (man, woman), age (continuous), method version (before or after September 1994), season (winter, spring, summer, autumn), total energy (continuous), education (<8 years, 9-10 years, $11-13$ years or university degree), smoking (current, ex or never), alcohol intake (zero, $<15 \mathrm{~g} / \mathrm{d}$ for women and $<20 \mathrm{~g} / \mathrm{d}$ for men, $15-30 \mathrm{~g} / \mathrm{d}$ for women and $20-40 \mathrm{~g} / \mathrm{d}$ for men, $>30 \mathrm{~g} / \mathrm{d}$ for women and $>40 \mathrm{~g} / \mathrm{d}$ for men), physical activity (quintiles of leisure-time
physical activity score) and BMI (continuous). 
toxins and bile acids, increase in colonic fermentation and an increase in colonic SCFA ${ }^{(6,25)}$. This may explain why our finding in general indicates intakes of fibre, and its food sources, to be inversely associated with tumours of the colon, but not of the rectum. However, we cannot exclude that it is a power issue, and we actually observed a tendency of inverse associations between high vegetable intake and risk for rectal cancer in men.

At a more cellular level in CRC development, cytoprotectants in fruits and berry, including vitamins, minerals, polyphenol flavonoids and anthocyanins, have been shown to have anticancer activity in colon cancer cell lines in vitro ${ }^{(26)}$. The antiproliferative effect of CRC cells by different berry juices was not correlated to the antioxidant level, but induced cell-cycle arrest in the $G_{1}$ phase ${ }^{(27)}$. The phenolic compounds vary with species, but there is strong evidence that these compounds modulate numerous cellular processes by up- or down-regulation of key proteins involved in cell signalling pathways that control gene expression, cell proliferation, cell differentiation, DNA damage repair, apoptosis, malignant transformation and inhibition of cell invasiveness and metastasis ${ }^{(28)}$. Our finding of a reduced risk for colon cancer in women with high intake of fruits and berries, in contrast to fibres from other sources, may be explained by the effect of phenolic compounds.

Participants who reported dietary change may have unstable food habits. Their reported dietary habits may reflect a short period of their lives, and may therefore have less influence on the development of future morbidity. However, as our low-risk estimates for CRC at higher intakes of fibre remained virtually unchanged after excluding those with dietary change, the loss of significance could probably be explained by a lower number of individuals (75.6\%) in the sensitivity analysis.

The strengths of this study are that the MDCS is a large study, with long follow-up. As it is a population-based prospective study, we should have been able to minimise selection bias and reverse causation. One of the main objectives of the MDCS was to examine fibre intake and estimated intakes of fibre, and its food sources have shown a high relative validity ${ }^{(12,13)}$. It was also possible to identify and exclude individuals with unstable food habits. In addition, we are not aware of any previous study taking TNM classification into consideration when examining associations between fibre intake and CRC. The participation rate of the MDCS is similar or higher compared with other largescale population-based studies ${ }^{(29)}$, and regarding the generalisability of our results it is important to point out that the socio-demographic structure, weight distribution and smoking habits were similar among participants in the MDSC and participants in a health survey in Malmö with a higher participation rate $(75 \%)^{(29)}$. Moreover, although the cancer incidence was somewhat higher among non-participants, $2.6 \%$ of the participants in the MDCS developed CRC during 15-year follow-up ${ }^{(30)}$, which is comparable to previously published data on other cohorts $^{(31)}$.

In analyses of different TNM stages, we observed significant associations only between high intake of fibre-rich cereals and lower risk for $\mathrm{N}$-stage 0 and $\mathrm{M}$-stage 0 . A possible interpretation is that potential effects of fibre on tumour initiation may differ from effects on tumour invasiveness and metastasis, and phenolic compounds referred to above may influence several steps in carcinogenesis ${ }^{(28)}$. However, a limitation of the study is the small number of cases in some of the stratified analyses and it cannot be excluded that the analyses of the other stages were underpowered because of fewer cases, and new studies in large populations are needed. It would, for example, be interesting to replicate the borderline association between fibre intake and risk for T-stage 3 and 4. Patient delay may also be a source of error in the TNM classification of the cases, as the time for the diagnosis can affect the outcome of the classification, without knowledge about the length of the tumour growth. There may also be a different pattern in when men and women visit healthcare services, thus giving them an earlier or later diagnosis. Women seem to have a tendency to be more inclined to participate in studies and to contact the healthcare service earlier in the disease process ${ }^{(32)}$. Another weakness of the study is that the collection of intake data was measured only once. As the results from a Swedish national survey on dietary intake has shown an increase in intakes of vegetables, fruit and berries ${ }^{(18)}$, repeated measurements would have been valuable. Because of different structuring after data gathering, it was not possible in the present study to estimate intakes of fibre from different fibre sources. Moreover, taking family history of CRC into account in our analyses would have been valuable, as it is a contributing factor in the development of $\mathrm{CRC}^{(33)}$, but information on the risk factor was missing. We have chosen not to adjust for multiple testing, as dietary intakes are highly correlated and the analyses could not be treated as independent. However, it should be noted that some of our subgroup associations could have occurred because of chance, as a consequence of multiple tests. Finally, despite adjustments for possible confounders and known risk factors, occurrence of some residual confounding cannot be excluded.

\section{Conclusion}

In conclusion, our findings indicate that a high fibre intake is associated with a lower risk for CRC, especially with a lower risk for colon cancer, in women. Regarding intakes of different fibre-rich foods, our results indicate that only high intakes of fruits and berries are associated with lower risk for colon cancer in women. Our findings suggesting that high intakes of fibrerich cereal products may lower the risk of developing N0- and M0-stage need to be replicated in future studies.

\section{Acknowledgements}

This research was funded by the Development foundation of Region Skåne and Dir Albert Påhlsson's Foundation (B. O.) and by the Malmö Hospital Foundation for Cancer Prevention. The Development foundation of Region Skåne and Dir Albert Påhlsson's Foundation had no role in the design, analysis or writing of this article.

A. V., B. O., J. M. and U. E. designed the research. A. V., B. O. and U. E. wrote the paper. A. V. performed the statistical analysis. K. J. and J. B. provided essential materials. U. E. had primary responsibility for the final content. All authors read and approved the final manuscript.

There are no conflicts of interest. 


\section{Supplementary material}

For supplementary material/s referred to in this article, please visit http://dx.doi.org/http://dx.doi.org/doi:10.1017/ S0007114515002743

\section{References}

1. Ferlay J, Parkin DM \& Steliarova-Foucher E (2010) Estimates of cancer incidence and mortality in Europe in 2008. Eur J Cancer 46, 765-781.

2. Edwards BK, Ward E, Kohler BA, et al. (2010) Annual Report to the Nation on the Status of Cancer, 1975-2006, featuring colorectal trends and impact of interventions (risk factors, screening, and treatment) to reduce future rates. Cancer 116, 544-573.

3. Bergman $\mathrm{O}$, Hont $\mathrm{G} \&$ Johansson E Cancer i siffror. Socialstyrelsen Cancerfonden; 2013. 20130605. http://www.socialstyrelsen.se/ Lists/Artikelkatalog/Attachments/19108/2013-6-5.pdf （accessed June 2014).

4. World Cancer Research Fund and American Institute for Cancer Research. Continuous Update Project Report. Food, Nutrition, Physical Activity, and the Prevention of Colorectal Cancer. (2011).

5. Murphy N, Norat T, Ferrari P, et al. (2012) Dietary fibre intake and risks of cancers of the colon and rectum in the European Prospective Investigation into Cancer and Nutrition (EPIC). PLOS ONE 7, e39361.

6. Azcarate-Peril MA, Sikes M \& Bruno-Barcena JM (2011) The intestinal microbiota, gastrointestinal environment and colorectal cancer: a putative role for probiotics in prevention of colorectal cancer? Am J Physiol Gastrointest Liver Physiol 301, G401-G424.

7. Chan AT \& Giovannucci EL (2010) Primary prevention of colorectal cancer. Gastroenterology 138, 2029-2043.

8. Aune D, Chan DSM, Lau R, et al. (2011) Dietary fibre, whole grains, and risk of colorectal cancer: systematic review and doseresponse meta-analysis of prospective studies. BMJ 343, d6617.

9. Aune D, Lau R, Chan DS, et al. (2011) Nonlinear reduction in risk for colorectal cancer by fruit and vegetable intake based on metaanalysis of prospective studies. Gastroenterology 141, 106-118.

10. Brandstedt J, Wangefjord S, Borgquist S, et al. (2013) Influence of anthropometric factors on tumour biological characteristics of colorectal cancer in men and women: a cohort study. J Transl Med 11, 293.

11. Wirfalt E, Mattisson I, Johansson U, et al. (2002) A methodological report from the Malmo Diet and Cancer study: development and evaluation of altered routines in dietary data processing. Nutr J 1, 3.

12. Elmstahl S, Riboli E, Lindgarde F, et al. (1996) The Malmo Food Study: the relative validity of a modified diet history method and an extensive food frequency questionnaire for measuring food intake. Eur J Clin Nutr 50, 143-151.

13. Riboli E, Elmstahl S, Saracci R, et al. (1997) The Malmo Food Study: validity of two dietary assessment methods for measuring nutrient intake. Int J Epidemiol 26, Suppl. 1, S161-S173.

14. Wangefjord S, Manjer J, Gaber A, et al. (2011) Cyclin D1 expression in colorectal cancer is a favorable prognostic factor in men but not in women in a prospective, population-based cohort study. Biol Sex Differ 2, 10.

15. Kyro C, Skeie G, Dragsted LO, et al. (2012) Intake of whole grain in Scandinavia: intake, sources and compliance with new national recommendations. Scand J Public Health 40, 76-84.

16. Koh-Banerjee P, Franz M, Sampson L, et al. (2004) Changes in whole-grain, bran, and cereal fiber consumption in relation to 8-y weight gain among men. Am J Clin Nutr 80, 1237-1245.
17. Park Y, Hunter DJ, Spiegelman D, et al. (2005) Dietary fiber intake and risk of colorectal cancer: a pooled analysis of prospective cohort studies. JAMA 294, 2849-2857.

18. Riboli E \& Norat T (2003) Epidemiologic evidence of the protective effect of fruit and vegetables on cancer risk. $\mathrm{Am} \mathrm{J}$ Clin Nutr 78, Suppl., 559S-569S.

19. Agudo A, Slimani N, Ocke MC, et al. (2002) Consumption of vegetables, fruit and other plant foods in the European Prospective Investigation into Cancer and Nutrition (EPIC) cohorts from 10 European countries. Public Health Nutr 5, 1179-1196.

20. Wirfalt E, Hedblad B, Gullberg B, et al. (2001) Food patterns and components of the metabolic syndrome in men and women: a cross-sectional study within the Malmo Diet and Cancer cohort. Am J Epidemiol 154, 1150-1159.

21. Hebert JR, Ma Y, Clemow L, et al. (1997) Gender differences in social desirability and social approval bias in dietary selfreport. Am J Epidemiol 146, 1046-1055.

22. Livsmedelsverket. Riksmaten - vuxna 2010-11: Vad äter svenskarna? - Livsmedels- och näringsintag bland vuxna i Sverige (Riksmaten - Adults 2010-11. What do the Swedes eat? Food and nutrition intake among adults in Sweden). Uppsala, Sweden: Livsmedelsverket; 2012. http://www.slv.se/upload/dokument/ rapporter/mat_naring/2012/riksmaten_2010_ 2011_kortversion.pdf. (accessed 27 August 2014).

23. Braniste V, Leveque M, Buisson-Brenac C, et al. (2009) Oestradiol decreases colonic permeability through oestrogen receptor beta-mediated up-regulation of occludin and junctional adhesion molecule-A in epithelial cells. $J$ Physiol 587, pt 13, 3317-3328.

24. Vrachnis N, Zygouris D, Iliodromiti Z, et al. (2014) Probing the impact of sex steroids and menopause-related sex steroid deprivation on modulation of immune senescence. Maturitas 78, 174-178.

25. Fardet A (2010) New hypotheses for the health-protective mechanisms of whole-grain cereals: what is beyond fibre? Nutr Res Rev 23, 65-134.

26. Brown EM, Gill CI, McDougall GJ, et al. (2012) Mechanisms underlying the anti-proliferative effects of berry components in in vitro models of colon cancer. Curr Pharm Biotechnol 13, 200-209.

27. Boivin D, Blanchette M, Barrette S, et al. (2007) Inhibition of cancer cell proliferation and suppression of TNF-induced activation of NFkappaB by edible berry juice. Anticancer Res 27, 937-948.

28. Duthie SJ (2007) Berry phytochemicals, genomic stability and cancer: evidence for chemoprotection at several stages in the carcinogenic process. Mol Nutr Food Res 51, 665-674.

29. Boeing H, Korfmann A \& Bergmann MM (1999) Recruitment procedures of EPIC-Germany. European investigation into cancer and nutrition. Ann Nutr Metab 43, 205-215.

30. Manjer J, Carlsson S, Elmstahl S, et al. (2001) The Malmo Diet and Cancer Study: representativity, cancer incidence and mortality in participants and non-participants. Eur J Cancer Prev 10, 489-499.

31. Howlader N, Noone A, Krapcho M, et al. (2014) SEER Cancer Statistics Review, 1975-2011. Bethesda: National Cancer Institute;

http://seer.cancer.gov/archive/csr/1975_2011/results_merged/ sect_06_colon_rectum.pdf (accessed 17 June 2015).

32. Briscoe ME (1987) Why do people go to the doctor? Sex differences in the correlates of GP consultation. Soc Sci Med 25, 507-513.

33. Butterworth AS, Higgins JP \& Pharoah P (2006) Relative and absolute risk of colorectal cancer for individuals with a family history: a meta-analysis. Eur J Cancer 42, 216-227. 